du Congo, et le fait que les Hollandais soit disant plus modernes, en fait, copient le modèle portugais, selon eux plus fonctionnel pour la stabilité du commerce.

Tous débats historiographiques modernistes plus qu'utiles pour des contemporanéistes!

Novembre 2008, Michel Gahen

\title{
Élodie Brun, Les relations entre l'Amérique du Sud et le Moyen-Orient. Un exemple de relance Sud-Sud, Paris, L'Harmattan, 2008, 198 pages, ISBN: 978-2-296-05561-2.
}

A política internacional tem se revelado um cenário produtor de ações sociais desconcertantes e de difícil interpretação. A sobrepujança do interesse econômico às vezes tem perdido espaço para iniciativas políticas inexplicáveis. A disposição para a guerra em alguns casos tem cedido a frágeis intervenções diplomáticas. Hostilidades históricas entre países têm sido ignoradas por gestos particulares de solidariedade entre seus cidadãos. E, pelo contrário, quando tudo faz crer que tal cenário começa a reunir as condições necessárias a sua democratização, atos de força são empreendidos pelas grandes potências, como que se quisessem nos mostrar que existem limites ao jogo de cena da harmonia entre os Estados.

Assim, embora muitos insistam na profundidade do antagonismo entre as escolas da «Teoria das Relações Internacionais » e queiram a todo custo encerrar o debate com a descoberta de alguma evidência incontestável, o fato é que essa é uma disciplina que tem se revelado inusitadamente profícua, com as portas permanentemente abertas para o surgimento de novas interpretações.

O estudo Les relations entre l'Amérique du Sud et le Moyen-Orient, que analisa as ações recentes de aproximação entre essas duas regiões, proporciona um retrato muito preciso de um tipo de movimento que aturde os analistas, por não encontrar explicações em interesses racionais claros e objetivos e por se nutrir de um conjunto de circunstâncias complexas que envolvem a evolução política interna desses países e suas formas de inserção internacional.

Por que essas duas regiões iniciaram uma aproximação neste momento? Por que procurar parceiros tão distantes? Quão nova é essa aproximação? Quais modalidades, entre aquelas já consagradas ou inventadas, são empregadas nesse movimento? Quais efeitos essa aproximação pode causar não apenas para os países envolvidos, mas sobre toda a articulação do sistema internacional? Essas são algumas questões que Élodie Brun, sua autora, pretende abordar ao longo desse texto.

Para proceder à sua análise, a autora elegeu quatro estudos de caso e nos vai provando a pertinência de sua escolha ao longo da dissertação, através de uma construção lenta do seu objeto. À primeira vista, ela se baseia em um critério geográfico - dois países sul-americanos, Brasil e Venezuela, e dois pertencentes à órbita do Oriente Médio, Egito e Irã. Em seguida, porém, aprendemos que a escolha de Brun se mostra mais complexa: Brasil e Egito são países que buscam exercer um estilo suave de política externa, utilizando a própria estrutura do sistema para inserir-se de forma mais plena, sem deixar, no entanto, de aspirar à 
sua reforma ou criar estruturas paralelas a ele. Irã e Venezuela, por sua vez, esforçam-se para ocupar uma posição de ruptura em relação a um sistema que julgam incapaz de responder a seus pleitos e procuram criar uma agenda própria, embora não logrem distanciar-se de todo das instâncias internacionais já consolidadas.

Élodie Brun constrói sua dissertação engenhosamente, alternando-se na descrição dos quatro casos e emprestando pouco a pouco densidade a sua análise. Para tanto, debruça-se no estudo das reuniões que selaram até o presente momento a aproximação, sendo a mais importante delas a Cúpula de Brasília, que criou iniciativa Aspa, para a associação entre a América do Sul e os Países árabes, em maio de 2005 (cuja Declaração Final consta dos anexos). Analisa os discursos dos chefes de Estado e recolhe a avaliação de especialistas políticos das duas regiões. Amplia seu objeto de estudo, detendo-se nas iniciativas bilaterais e multilaterais empreendidas por cada um desses Estados. Realiza, portanto, uma recolta de dados inédita e extremamente útil sobre o movimento que deseja analisar, enriquecida especialmente pela adoção do método comparativo, que se demonstra não somente pertinente como também particularmente revelador das motivações e dos métodos empregados por Brasil, Venezuela, Irã e Egito.

Sua tese é de que, como demonstra seu objeto de estudo, de fato existe um movimento de reorganização do Sul, que este é um fenômeno que se solidifica e que cria formas novas de movimentar-se no espaço internacional, através de iniciativas de associação menos formais porque menos atreladas aos interesses primordiais de cada país. A autora, entretanto, revela dúvidas sobre o futuro desse movimento, inquieta-se pela falta de coesão dos países do Sul, pelas diferenças de estilo, pelas incoerências intermitentes de cada país, pela escassez de seus meios para provocar uma profunda alteração do sistema internacional.

A autora não reclama nitidamente atrelamento a nenhuma corrente da «Teoria das Relações Internacionais », mas sua metodologia permite situá-la no seio da escola realista. Alguns elementos autorizam tal avaliação. O primeiro deles é a compreensão de que o fato social essencial da política internacional é a ação dos Estados, o que permite ao estudo concentrar-se na análise das reuniões diplomáticas, visitas bilaterais, discursos de chefe de Estado, criação de blocos multilaterais, etc. De fato, a diplomacia adquiriu na história moderna a feição de uma estrutura estatal, movida por funcionários públicos formados e pagos pelo Estado, mas sua história mais longínqua contém episódios nos quais ela foi praticada por movimentos alheios ao Estado e sua história recentíssima revela a criação de estruturas destinadas a realizar atividades diplomáticas cuja origem é supra-estatal, organizadas antes em função de temas de discussão do que da defesa dos interesses de uma nacionalidade.

O segundo elemento está na atenção que dispensa à personalidade dos chefes de Estado e dos atores que os circundam - o que a autora legitima agora sim reivindicando os ensinamentos da escola cognitiva, filiada ao realismo. Assim, disserta sobre a personalidade dos chefes de Estado dos seus quatro países-objeto e de seus principais assessores. É verdade que em regimes presidencialistas a personalidade do chefe de Estado tem algum peso sobre a forma como a política é conduzida, mas utilizá-la para explicar opções, escolhas de estratégias ou escolha de parceiros pode levar a conclusões enviesadas. Um exemplo está na relação 
que faz a autora da opção de Hugo Chávez de aproximar-se dos países árabes provavelmente influenciado por um assessor de idéias anti-semitas - raciocínio que subtrai muito da profundidade das coordenadas que determinam a elaboração da política externa venezuelana.

Finalmente, o apego da autora à sua análise factual das ações dos Estados a distancia de uma imersão profunda na história e nas coordenadas da evolução política dos países em questão. Se é verdade que os quatro países exercem uma diplomacia primordialmente estatal, é verdade também que suas decisões de Estado têm origem nos movimentos socio-políticos que permitiram que essas lideranças chegassem ao poder, que suas decisões (ainda que de cunho autoritário, em alguns dos casos) associam-se às formas praticadas por esses governos de relacionar-se com suas sociedades, que seus atos de política externa atrelam-se à história de suas diplomacias, cuja combatitividade, em alguns casos, não data de hoje.

Os dois casos sul-americanos são exemplares da necessidade de uma prospecção histórica mais ampla para a análise de suas políticas externas. A chegada ao poder de Lula e Chávez responde a uma evolução política inédita de uma região que, apesar de ter se livrado do pacto colonial há quase duzentos anos, jamais logrou fazer ascender ao poder representantes de classes sociais desassociadas dos antigos colonizadores. A emergência dessas novas lideranças traz desdobramentos importantes não somente para a dinâmica política interna, mas também sobre suas formas de exercer a política externa, que responderá certamente a aspirações sociais profundas e às novas necessidades discursivas dos segmentos sociais, antes órfãos, que agora foram os responsáveis pela mudança no poder.

No que concerne o Oriente Médio, cuja tensão política é sempre tratada sob a ótica da política externa, desencadeada pela criação e posterior expansão pela força do Estado de Israel, seria necessário igualmente uma imersão sócio-histórica para compreender o quanto as aspirações sociais dos povos em questão influenciam o estilo de seus governantes, a emergência de lideranças autoritárias, os processos de radicalização da prática do islã por que passam algumas sociedades, e, pelo contrário, a necessidade de alianças com os Estados Unidos e a opção pela política suave praticada pelo Egito.

Ao atrelar-se à análise dos fatos recentes da aproximação entre a América do Sul e o Oriente Médio, a autora se depara sobre suas dificuldades de coesão, os antagonismos que se produzem no seio de suas tentativas de associação e ao que ela chama de uma «competição pela liderança do Sul», que atrasaria a realização de seus interesses comuns. Essa visão remete mais uma vez ao debate realista sobre o equilíbrio de poder (unipolar, bipolar ou multipolar), segundo o qual todos os atores estariam em busca de assumir o topo da pirâmide. Talvez a mais importante conclusão a que o estudo de tal caso poderia levar não é a de um Sul tentando se organizar para contrapor-se ao Norte ou para fazer valer interesses comuns objetivos e minuciosamente definidos. É mesmo difícil supor que tais interesses possam vir a existir, que Brasil e Irã partilhem juntos um pleito nítido, ou que Venezuela e Egito se unam para conseguir uma concessão qualquer das potências mundiais, ou ainda, mais inusitadamente, que a iniciativa América do Sul - Países árabes logre ao menos definir uma plataforma concreta que coloque as duas regiões numa mesma trincheira. O mais importante está no movimento de aproximação, no desencadeamento de minúsculas iniciativas de cooperação, na 
abertura de canais para o conhecimento mútuo e que tudo isso venha, finalmente, contribuir para algum tipo de democratização do sistema internacional.

Esses são caminhos de reflexão que decorrem da opção teórica e do decorrente encaminhamento metodológico que cada pesquisador confere a seu trabalho. Nada, porém, subtrai a importância do estudo de Brun. A reunião de elementos empíricos realizada neste trabalho é preciosa e as portas para seu aprofundamento estão abertas nas entrelinhas da própria dissertação. As páginas dedicadas, por exemplo, à relação dos países em questão com Israel são inéditas, mostram ímpeto de ampliação das coordenadas utilizadas para a análise e abrem também um canal para a consideração de aspectos sociais na análise da política externa, quando se referem às pressões decorrentes das comunidades provenientes de países árabes na América do Sul sobre a forma como seus Estados definem seus parceiros.

O mérito principal deste estudo é o de captar um movimento novo do panorama político internacional e atribuir-lhe relevância. Élodie Brun mostra que o movimento de aproximação entre as duas regiões não é um mero dispêndio inconseqüente de energia diplomática, mas um fenômeno novo da política internacional, que pode ter efeitos sobre sua forma de organização e sua transparência.

Novembro de 2008, Juliana Santil

\section{Olivier Dabène (ed.), Amérique latine, les élections contre la démocra-} tie ?, Paris, Les Presses de Science Po., 2007, 381 p., ISBN : 978-2-7246-1039-0.

Há trinta anos inciava-se a Terceira Onda democrática na América latina com a abertura dos regimes políticos na República dominicana (1978) e no Equador (1979), um processo de magnitude inigualável na região pela sua abrangência e duração. Hoje, a democracia é a regra, e não mais a exceção entre os Estados latinoamericanos. Apesar de algumas contramarchas, especialmente nos países andinos, a democracia mostrou-se, ao contrário do que imaginavam muitos observadores no início dos anos 1980, capaz de se fortalecer na região ${ }^{1}$.

Mesmo após três décadas, não é fácil avaliar os impactos da Terceira Onda. Institucionalmente, a avaliação parece positiva. Os regimes democráticos sobreviveram em ambientes inóspitos, marcados pela tradição autoritária e sucessivas crises econômicas. Foram também, ainda que lentamente, capazes de incorporar atores políticos antes marginalizados e suportar a alternância de poder, como mostrou a onda eleitoral que varreu a região entre novembro de 2005 e dezembro de 2006, na qual oito candidatos a presidente localizados à esquerda no espectro político foram eleitos. Sob o ponto de vista socioeconômico, no entanto, o novo período democrático apresenta resultados tímidos. Segundo dados da Cepal, apesar dos avanços nos últimos anos, 33,2 \% dos latinoamericanos ainda vivem abaixo da linha da pobreza - uma redução de apenas 7,3 pontos percentuais

\footnotetext{
${ }^{1}$ Sobre a Terceira Onda na América latina ver F. HAgopian \& S. Mainwaring (eds), The Third Wave of Democratization in Latin America: Advances and Setbacks, Cambridge, Cambridge University Press, 2005.
} 